3 Pileri SA, Grogan TM, Harris NL, et al. Tumours of histiocytes and accessory dendritic cells: an immunohistochemical approach to classification from the International Lymphoma Study Group based on 61 cases. Histopathology 2002; 41: 1-29.

4 Farris AB 3rd., Mark EJ., Kradin RL, Pulmonary "inflammatory myofibroblastic" tumors: a critical examination of the diagnostic category based on quantitative immunohistochemical analysis. Virchows Arch 2007; 450: 585-590.

5 Chun YS, Wang L, Nascimento AG, et al. Pediatric inflammatory myofibroblastic tumour: anaplastic lymphoma kinase (ALK) expression and prognosis. Pediatr Blood Cancer 2005; 45: 796-801.

6 Fukano R, Matsubara T, Inoue $\mathrm{T}$, et al. Time lag between the increase of IL- 6 with fever and NF- $\kappa$ B activation in the peripheral blood in inflammatory myofibroblastic tumour. Cytokine 2008; 44: 293-297.
7 Sato M, Takasaka I, Okumura T, et al. F-18 fluorodeoxyglucose accumulation in an inflammatory pseudotumor of the spleen. Ann Nucl Med 2007; 21: 521-524.

8 Reddy MP, Menda Y, Floresca J, et al. FDG positron emission tomographic imaging of pseudo-pseudo tumor. Clin Nucl Med 2002; 27: 445-446.

9 Reubi JC, Kappeler A, Waser B, et al. Immunohistochemical localization of somatostatin receptors sst2A in human tumors. Am J Pathol 1998; 153: 233-245.

10 Paran D, Paran H. Somatostatin analogs in rheumatoid arthritis and other inflammatory and immune-mediated conditions. Curr Opin Investig Drugs 2003; 4: 578-582.

DOI: $10.1183 / 09031936.00053609$

\title{
Selective apoptosis of lung cancer cells with talc
}

\section{To the Editors:}

Lung cancer is the leading cause of cancer deaths worldwide, with adenocarcinoma being the most common cell type. The majority of patients with lung cancer present at an advanced stage of disease with only $15 \%$ being amenable to surgery for cure; treatment is, therefore, palliative. For patients with malignant effusions due to pleural metastasis, chemical pleurodesis is one method by which to prevent recurrence. While there are many intrapleural sclerosing agents, most data pertaining to pleurodesis have been reported with tetracycline derivatives, bleomycin and talc [1].

A number of studies have demonstrated superior efficacy of talc over other sclerosing agents commonly used for the palliation of malignant pleural effusions [2], and talc is the preferred pleurodesis agent according to a survey of chest physicians [3]. Despite talc's wide clinical use, the exact mechanisms for its efficacy as well as its apoptotic effects on lung cancer cells in vitro have not been studied. The objectives of our study were to determine if talc caused apoptosis of lung cancer cells, and to compare talc against other commonly administered intrapleural sclerosing agents by extending the experiments to include bleomycin and doxycyline.

The lung adenocarcinoma cell line (LAC, A549) was purchased from American Type Culture Collection (Rockville, MD, USA). Human pleural mesothelial cells (PMC) characterised by classic cobblestone morphology, cytokeratin and without factor VIII antigen were isolated from pleural fluid obtained via thoracentesis from patients with symptomatic transudative pleural effusions secondary to congestive heart failure, and without evidence of infection. Written informed consent was obtained from all patients and performed in accordance with the protocol approved by the institutional review board (Singapore General Hospital, Singapore).

Both PMC and LAC were maintained in RPMI-1640 culture medium (Gibco Laboratory, Long Island, NY, USA) and 10\% fetal calf serum (Hyclone, Logan, UT, USA) at $37^{\circ} \mathrm{C}$, in $5 \% \mathrm{CO}_{2}$, $95 \%$ air and $100 \%$ humidity.

Talc particles measuring $2 \mu \mathrm{m}$ were prepared using density gradient separation (Ficoll Hypaque ${ }^{\mathrm{TM}}$ Plus; Amersham Pharmacia, Amersham, UK), and confirmed against silicone beads of the same size (Becton Dickinson, San Jose, CA, USA) as reference under an inverted microscope (CK-X31; Olympus, Tokyo, Japan). Talc was applied as a suspension in endotoxinfree normal saline while parenteral formulations of bleomycin and doxycycline were prepared using aseptic techniques. Equal numbers of PMC and LAC were exposed to 25, 50 and $75 \mu \mathrm{g} \cdot \mathrm{mL}^{-1}$ of talc, bleomycin and doxycycline, and cellular apoptosis was measured with propidium iodide staining and flow cytometry at 24, 48 and $72 \mathrm{~h}$. Washed and autoclave sterilised silicone beads at equivalent concentrations were used as parallel control.

At specified time intervals, LAC and PMC were harvested from cultures using $0.125 \%$ trypsin solution, washed with PBS (Gibco) and fixed with ethanol. They were stained with propidium iodide solution $\left(5 \mu \mathrm{g} \cdot \mathrm{mL}^{-1}\right.$; Sigma Aldrich, St Louis, MO, USA) containing $0.1 \%$ triton X-100 and RNase A [4]. DNA contents of target cells were analysed using fluorescence-activated cell sorter Calibur flow cytometer and CellQuest Pro software (Becton Dickinson) as described previously [5], and the sub-G1 population was identified as the marker for apoptosis (fig. 1). Experiments were performed in triplicate at each time-point and for each cell line. Cellular apoptosis measuring $<3 \%$ was considered as baseline rate. Multiple comparisons were performed with ANOVA, and $\mathrm{p} \leqslant 0.05$ was considered statistically significant.

Differences in the apoptosis rates of LAC were observed with graded concentrations of talc, bleomycin, and doxycycline at $24 \mathrm{~h}(\mathrm{p}=0.009), 48 \mathrm{~h}(\mathrm{p}=0.006)$ and $72 \mathrm{~h}(\mathrm{p}=0.01)$. Talc induced apoptosis of LAC in a dose- and time-dependent manner which was superior to bleomycin but inferior to doxycycline (table 1). No apoptosis of PMC was documented with talc but 


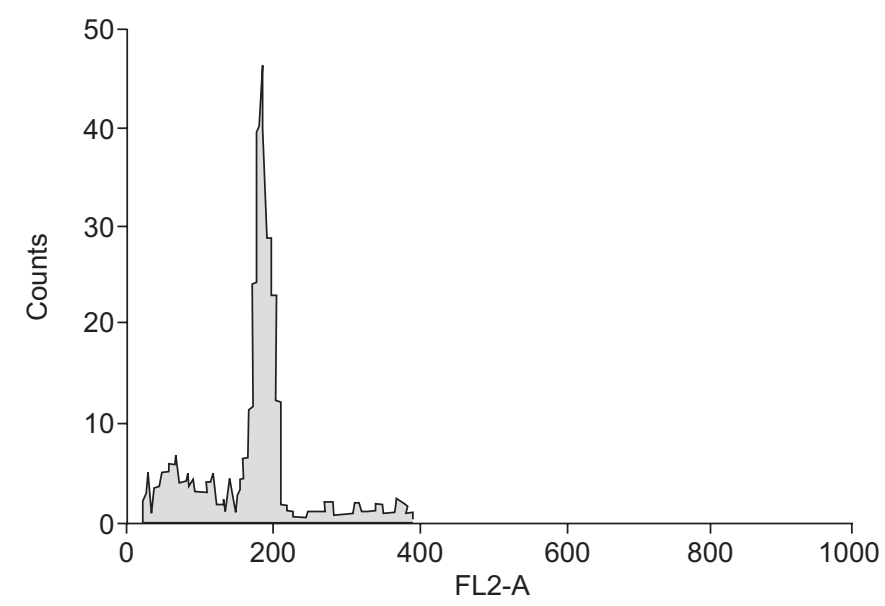

FIGURE 1. Apoptosis measurement of lung adenocarcinoma cells with talc $\left(75 \mu \mathrm{g} \cdot \mathrm{mL}^{-1}\right)$ at 72 h. G0/G1: 52.56\% 5: 11.30\%; G2/M: 9.94\%; Apoptotic: $26.2 \%$.

it was observed with doxycycline and, to a lesser degree, with bleomycin at $72 \mathrm{~h}(\mathrm{p}=0.001)$. At increasing concentrations of silicone beads being used as controls, there was no increase of apoptosis over baseline of both LAC and PMC (fig. 2).

Malignant pleural effusion is a common complication of advanced lung cancer in which survival is $<6$ months. Treatment focuses on palliation of symptoms, which can often be achieved by the drainage of pleural fluid. Pleurodesis with a chemical sclerosant is one method to prevent recurrence of malignant pleural effusions [1]. Talc administered as slurry or poudrage has demonstrated superior efficacy over tetracycline

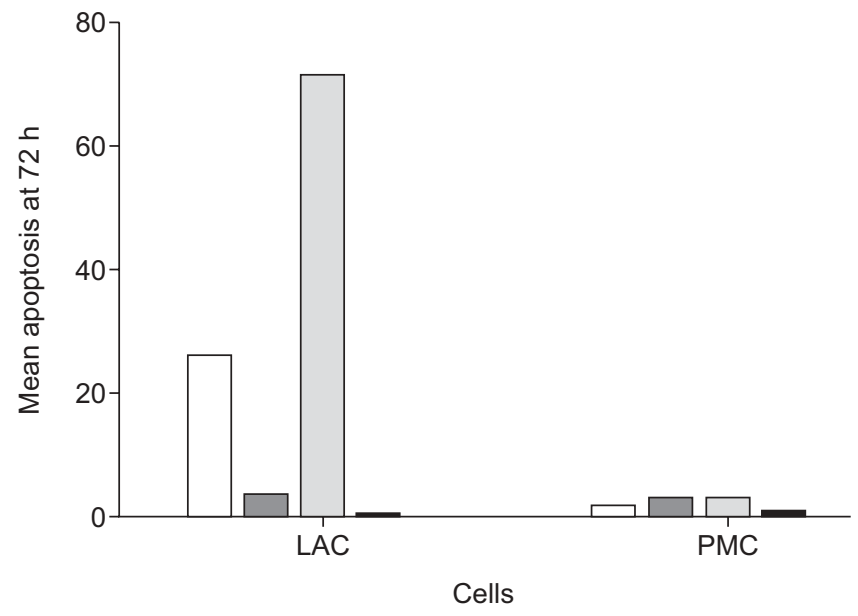

FIGURE 2. Comparison of agents $\left(75 \mu \mathrm{g} \cdot \mathrm{mL}^{-1}\right)$ on apoptosis of lung adenocarcinoma cells (LAC) and pleural mesothelial cells (PMC) at 72 h. $\square$ : talc; 口: bleomycin; $\mathbf{\square}$ : doxycycline; $\mathbf{\square}$ : silicone beads control.

derivatives and bleomycin $[2,6]$. Moreover, clinical reports suggest that patients with malignant pleural effusions that have been successfully pleurodesed with talc experience improved quality of life, and may lead to prolonged survival [7].

Although talc, bleomycin and doxycycline are commonly administered into the pleural space to incite pleurodesis, it is not known if these agents have any local effects on metastatic lung cancer or pleural mesothelial cells. Our study demonstrates that talc causes apoptosis of lung cancer cells in a dose- and time-dependent manner. When these agents are

TABLE 1 Talc and apoptosis of pleural mesothelial cells and lung adenocarcinoma

Agent

Apoptosis measurement ${ }^{\#}$

\begin{tabular}{|c|c|c|c|c|c|c|c|c|}
\hline & \multicolumn{4}{|c|}{ Lung adenocarcinoma } & \multicolumn{4}{|c|}{ Pleural mesothelial cells } \\
\hline & $\mathbf{O h}$ & $24 \mathrm{~h}$ & $48 h$ & $72 \mathrm{~h}$ & O h & $24 \mathrm{~h}$ & $48 h$ & $72 \mathrm{~h}$ \\
\hline \multicolumn{9}{|l|}{ Talc } \\
\hline $25 \mu \mathrm{g} \cdot \mathrm{mL}^{1}$ & 0.2 & 1.6 & 6.2 & 12.0 & 0.1 & 0.1 & 0.3 & 0.6 \\
\hline $50 \mu \mathrm{g} \cdot \mathrm{mL}^{-1}$ & 0.2 & 5.9 & 9.6 & 16.0 & 0.1 & 0.1 & 0.1 & 1.4 \\
\hline $75 \mu \mathrm{g} \cdot \mathrm{mL}^{-1}$ & 0.2 & 5.9 & 16.4 & 26.2 & 0.1 & 0.1 & 0.2 & 1.6 \\
\hline \multicolumn{9}{|l|}{ Bleomycin } \\
\hline $25 \mu \mathrm{g} \cdot \mathrm{mL}^{-1}$ & 0.1 & 0.2 & 1.5 & 2.4 & 0.1 & 0.1 & 0.6 & 2.1 \\
\hline $50 \mu \mathrm{g} \cdot \mathrm{mL}^{-1}$ & 0.2 & 0.2 & 2.2 & 2.5 & 0.1 & 0.1 & 1.0 & 2.5 \\
\hline $75 \mu \mathrm{g} \cdot \mathrm{mL}^{-1}$ & 0.5 & 0.5 & 2.3 & 3.7 & 0.1 & 0.3 & 1.5 & 3.0 \\
\hline \multicolumn{9}{|l|}{ Doxycycline } \\
\hline $25 \mu \mathrm{g} \cdot \mathrm{mL}^{-1}$ & 0.2 & 11.2 & 16.4 & 23.1 & 0.1 & 1.4 & 9.6 & 12.6 \\
\hline $50 \mu \mathrm{g} \cdot \mathrm{mL}^{-1}$ & 0.2 & 33.1 & 33.4 & 46.5 & 0.1 & 10.1 & 14.2 & 19.2 \\
\hline $75 \mu \mathrm{g} \cdot \mathrm{mL}^{-1}$ & 0.1 & 39.4 & 45.0 & 71.5 & 0.6 & 14.1 & 17.8 & 27.6 \\
\hline \multicolumn{9}{|c|}{ Silicone beads } \\
\hline $25 \mu \mathrm{g} \cdot \mathrm{mL}^{-1}$ & 0.1 & 0.1 & 0.1 & 0.1 & 0.1 & 0.1 & 0.1 & 0.1 \\
\hline $50 \mu \mathrm{g} \cdot \mathrm{mL}^{-1}$ & 0.1 & 0.2 & 0.1 & 0.1 & 0.1 & 0.1 & 0.1 & 0.7 \\
\hline $75 \mu \mathrm{g} \cdot \mathrm{mL}^{-1}$ & 0.1 & 0.2 & 0.1 & 0.1 & 0.1 & 0.3 & 0.1 & 0.8 \\
\hline
\end{tabular}

Data are presented as \% and represent the median of three independent studies. Experiments were performed in triplicates at each time-point and for each cell line

\#: apoptosis of lung cancer cells and pleural mesothelial cells was measured with propidium iodide staining and flow cytometric analysis. 
compared, talc not only causes a greater degree of apoptosis of lung cancer cells than bleomycin at equivalent concentrations, but it also demonstrates selectivity of action by sparing the normal mesothelium, which is not observed with bleomycin or doxycyline. Our in vitro observation was further supported by the discovery of a preserved layer of mesothelial cells despite an intense inflammatory pleural reaction in rabbits treated with talc [8].

Interactions between normal PMC and tumour cells are complex. An intact pleural mesothelium appears important for inciting the acute inflammatory response necessary for pleurodesis by secreting pro-inflammatory interleukin- 8 and vascular endothelial growth factor, and for developing pleural fibrosis by the production of transforming growth factor- $\beta$ and basic fibroblast growth factor [8,9]. ANTONY et al. [9] demonstrated that patients with extensive pleural carcinomatosis and minimal intervening normal mesothelium had significantly lower quantities of basic fibroblast growth factor in their pleural fluid, compared to those with limited disease who subsequently developed successful pleural symphysis. These findings suggested that a mesothelium free of tumour was necessary for successful pleurodesis [8]. A recent study also showed that an intact pleural mesothelium is critical in modulating the metastatic potential of cancer cells within the pleural space. Malignant cells secrete angiogenic factors that promote tumour growth, proliferation of endothelial cells and invasion of surrounding tissue by neovascularisation. Talc treated pleural mesothelium counteracts these effects by releasing endostatin, an antiangiogenic factor which may be responsible for tumour containment within the pleural space, and account for the improved clinical outcome of patients with malignant pleural effusions successfully pleurodesed with talc [10].

Our preliminary results support the use of talc for malignant effusion as it selectively causes apoptosis of lung cancer cells, and spares normal mesothelium pivotal for inciting inflammatory processes necessary for pleural fibrosis. Studies are underway to compare the in vitro results with in vivo response, as well as to assess the impact on patient survival.

\section{P. Lee*, L. Sun", C.K. Lim", S.E. Aw ${ }^{\#}$ and H.G. Colt}

*Depts of Respiratory and Critical Care Medicine, and "Dept of Clinical Research, Singapore General Hospital, Singapore. TPulmonary and Critical Care Medicine, UC Irvine Medical Center, Orange, CA, USA.
Correspondence: P. Lee, Dept of Respiratory and Critical Care Medicine, Singapore General Hospital, Outram Road, Singapore 169608. E-mail: lee.pyng@sgh.com.sg

Support Statement: This study was supported by a grant from the Dept of Clinical Research (Singapore General Hospital, Singapore).

Statement of Interest: None declared.

Acknowledgements: We would like to thank G. Lee (Dept of Respiratory Medicine, University of Western Australia, Perth, Australia) for his invaluable critique of the manuscript, and S. Fook (Dept of Clinical Research, Singapore General Hospital, Singapore) for her statistical input.

\section{REFERENCES}

1 Antunes G, Neville E, Duffy J, et al. BTS guidelines for the management of malignant pleural effusions. Thorax 2003; 58: Suppl. 2, ii29-ii38.

2 Shaw P, Agarwal R. Pleurodesis for malignant pleural effusions. Cochrane Database Syst Rev 2004; 1: CD002916.

3 Lee YC, Baumann MH, Maskell NA, et al. Pleurodesis practice for malignant pleural effusions in five English-speaking countries: survey of pulmonologists. Chest 2003; 124: 2229-2238.

4 Toh HC, Sun L, Koh CH, et al. Vinorelbine induces apoptosis and caspase-3 (CPP32) expression in leukemia and lymphoma cells: a comparison with vincristine. Leuk Lymphoma 1998; 31: 195-208.

5 Tan DT, Liu YP, Sun L. Flow cytometry measurements of DNA content in primary and recurrent pterygia. Invest Ophthalmol Vis Sci 2000; 41: 1684-1686.

6 Hartman DL, Gaither JM, Kesler KA, et al. Comparison of insufflated talc under thoracoscopic guidance with standard tetracycline and bleomycin pleurodesis for control of malignant pleural effusions. J Thorac Cardiovasc Surg 1993; 105: 743-747.

7 Viallat JR, Rey F, Astoul P, et al. Thoracoscopic talc poudrage pleurodesis for malignant effusions. A review of 360 cases. Chest 1996; 110: 1387-1393.

8 Marchi E, Vargas FS, Acencio MM, et al. Evidence that mesothelial cells regulate the acute inflammatory response in talc pleurodesis. Eur Respir J 2006; 28: 929-932.

9 Antony VB, Nasreen N, Mohammed KA, et al. Talc pleurodesis: basic fibroblast growth factor mediates pleural fibrosis. Chest 2004; 126: $1522-1528$.

10 Nasreen N, Mohammed KA, Brown S, et al. Talc mediates angiostasis in malignant pleural effusions via endostatin induction. Eur Respir J 2007; 29: 761-769.

DOI: $10.1183 / 09031936.00113109$

\section{Nonresolving pneumonia and rash in an adult: pulmonary involvements in Kawasaki's disease}

\section{To the Editors:}

Slowly resolving or nonresolving pneumonia is a challenge for physicians. The most common clinical error when approaching these patients is to subsequently treat the patient with different antibiotics over an extended period of time, without questioning the cause of treatment failure. Mostly, slowly resolving pneumonias are due to host defence or infectious causes. Nonresolving pneumonias are usually of noninfectious origin and, in the majority of cases, require invasive diagnostic 